\title{
Nozick's Real Argument for the Minimal State*
}

\author{
KEITH HYAMS \\ (Published in The Journal of Political Philosophy 12.3 (September 2004) 353-364)
}

\begin{abstract}
Nozick is often interpreted as arguing that independents are entitled to protection by the Dominant Protective Agency (DPA) because the DPA infringes their right to punish those who violate their rights. Yet a closer look at Anarchy, State and Utopia reveals that Nozick actually rejects the very argument which is commonly attributed to him, and that he does so for good reason. However, I argue that Nozick's replacement principle of compensation for disadvantage, meant to ground his real argument for independents' entitlement to protection by the DPA, ought to be unacceptable to a libertarian. I end by suggesting an alternative to it, which I think remains faithful to basic libertarian principles.
\end{abstract}

\section{THE MINIMAL STATE}

To qualify as a state, Nozick claims, an association must as a minimum condition have 'the requisite sort of monopoly over the use of force in the territory' and it must protect 'the rights of everyone in the territory, even if this universal protection could be provided only in a "redistributive" fashion'. In part one of Anarchy, State and Utopia, Nozick sets himself the formidable task of demonstrating that such a state could arise, with no morally impermissible steps, from a Hobbesian style 'state of nature'. What makes his task difficult is that for Nozick,

\footnotetext{
${ }^{*}$ I would like to thank two referees for their comments on an earlier version of this article.

${ }^{1}$ Nozick 1974, p. 113; see also pp. 26-27
} 
morally permissibility is to be judged according to libertarian standards, with their emphasis on the protection of property rights and freedom from interference.

The story begins with the emergence of a 'dominant protective agency' (DPA), a private enforcement agency which hires out its protection and which, over time, has achieved dominance over competing agencies in a certain geographical area. The DPA does not yet, however, satisfy the condition for statehood, since the existence of several 'independents' who choose to exercise 'self-help' enforcement of their rights rather than hire the DPA's services, means that the DPA does not yet enjoy a monopoly on the use of force in its territory. Nozick faces two problems in showing how the DPA could acquire, without any morally impermissible steps, the role of universal force provider, which would allow it to be considered a minimal state. First, he must show how libertarian morality can permit the DPA to exercise a monopoly on force by preventing agents from exercising self-help enforcement of their rights. Such prevention would, prima facie, seem to constitute a morally impermissible instance of interference for a libertarian. Second, he must explain why the DPA is obliged to protect the rights of everyone in the territory, even if that requires redistributive taxation to pay for the protection of those who do not voluntarily hire the DPA's protective services. Once again, such redistributive taxation seems, at first sight, distinctly unlibertarian.

Nozick's argument for the minimal state constitutes one of the most difficult and tangled sections of Anarchy, State, and Utopia, such that it has been left to his commentators to try to elucidate the argument which Nozick thinks justifies the move from the DPA to the minimal state. In this paper I argue that several commentators have hitherto misunderstood the central point of Nozick's argument. There has been a tendency to interpret Nozick as defending, in whole or in part, an argument which I will call the 'argument from encroachment'. However, Nozick actually rejects this argument, and his reasons for doing so are entirely convincing. 


\section{THE COMPENSATION FOR ENCROACHMENT PARADIGM}

One way in which one may take on a positive obligation to do something in the context of a Nozickean moral framework is by becoming obliged to provide reparations for having infringed the rights of another party. I will follow Thomson and Feinberg in making use of a distinction between infringing rights and violating rights. ${ }^{2}$ If one agent has a right that $\mathrm{X}$ not be brought about, then another agent infringes that right if she brings $\mathrm{X}$ about. A violation of a right occurs when an agent infringes a right and when that infringement may be regarded as all things considered morally culpable. I will also make use of the phrase encroaching upon a right to refer to infringements which are not violations. An encroachment upon a right thus takes place when an agent infringes a right in a manner which is not all things considered morally culpable. ${ }^{3}$

Both violations of rights and encroachments of rights may (but need not) require the infringing agent to provide compensation to the agent whose rights are infringed. But since violations are all things considered morally impermissible, their intentional performance by the DPA cannot be condoned regardless of whether compensation is paid after the event. That is, Nozick cannot move from the DPA to the minimal state without any morally impermissible steps if he condones rights violations. Encroachments, on the other hand, occur when a right is infringed, but when the infringement is not all things considered morally culpable. As such, intentional encroachments can potentially feature in the move from the DPA to the minimal state, grounding a duty on the part of the DPA to compensate independents for having encroached upon their rights. When compensation is owed as a result of a rights encroachment,

\footnotetext{
${ }^{2}$ Thomson 1986, p. 51; Feinberg 1978, pp. 101-2. Note that, in defining 'violation', Thomson and Feinberg say simply 'wrong' rather than 'all things considered morally culpable'. I prefer to use the latter phrase, since the former leaves an ambiguity over whether the action was permissible overall (one might say of an act, 'It was wrong, but in the circumstances excusable').

${ }^{3}$ The distinction between violations and encroachments corresponds to Nozick's distinction between 'permissible' and 'impermissible' boundary crossings.
} 
let us say that the compensation for encroachment paradigm applies. In order for an infringement of a right to be considered an encroachment rather than a violation, there must be some moral sanction for the infringement which prevents the infringement from being all things considered morally culpable (which, in the absence of the sanction, it would be). ${ }^{4}$ Note, however, that although the presence of a moral sanction is a necessary condition for the applicability of the compensation for encroachment paradigm, it may not be a sufficient condition. For it is possible that some sanctions may not leave an obligation to compensate in their wake. Suppose, for example, that whilst rock climbing Emma and Harry get into trouble and Emma finds that the only way she can save Harry's life is by cutting his rope (that is, a rope that he owns, not just the rope that he is attached to). It seems to me that Emma is not obliged to buy Harry a new rope in compensation.

In order to defend the claim that the compensation for encroachment paradigm may be applied to the case of the DPA and the independent, one would have to show three things. First, that independents possess some right which the DPA has a motivation to infringe. Second, that some sanction exists which allows the infringement of the right to be treated as an encroachment rather than a prohibited violation. And third, that the sanction leaves an obligation to compensate in its wake.

\section{NOZICK AND THE ARGUMENT FROM ENCROACHMENT}

An argument of just this type is sometimes (mis)attributed to Robert Nozick. I will call it the argument from encroachment. According to this interpretation of Nozick, he argues that independents (along with everyone else) have a right to punish those who violate their rights. The DPA encroaches upon this right by enforcing a prohibition on self-help procedures for

\footnotetext{
${ }^{4}$ Unless the infringement took place by unculpable accident - but only intentional infringements are relevant to the case of the DPA and the independent.
} 
determining guilt and subsequent punishment. ${ }^{5}$ It enforces this prohibition in order to protect its clients against the potentially grave risk that such procedures will result in the punishment of an innocent client, or the punishment of a guilty client disproportionately to his crime. The DPA, however, is obliged to compensate independents for this encroachment. The cheapest way that it can do this is by protecting independents itself, as a replacement for the self-help protection that it prohibits (though only in conflicts with other clients, since the DPA need not interfere at all in disputes between independents and other independents).

Perhaps the clearest statement of this interpretation of Nozick is to be found in Jonathan Wolff's book on Nozick, where at one point he even says that this is the 'corner stone of Nozick's argument for the minimal state'. ${ }^{6}$ J. Wolff writes:

John Wayne [the independent] has a natural right to punish others, but the dominant agency refuses to allow him to exercise that right because of the risk of harm he will do misusing that right. But, Nozick argues, if it prohibits him from using his natural right the dominant agency must compensate him for this. ${ }^{7}$

On this interpretation, Nozick's postulation of a procedural right 'to be shown that [one] is being handled by some reliable and fair system' is supposed to provide the sanction for the DPA's infringement, thus making it an encroachment rather than a violation. ${ }^{8}$ That is to say, clients accused of a crime have a procedural right to be tried by a system of justice which is 'fair and reliable', and they may thus authorise the DPA to enforce this right on their behalf by prohibiting the use of unreliable self-help methods. ${ }^{9}$ Alternatively, since Nozick recognises that the assumption of procedural rights may be problematic, he suggests (on this interpretation) as an alternative route to roughly the same conclusion the 'epistemic border crossing principle'

\footnotetext{
${ }^{5}$ See, for example, Nozick 1974, p. 110

${ }^{6} \mathrm{~J}$. Wolff 1991, p. 61. Elements of this interpretation, sometimes hybridised with what I will argue below is a correct interpretation of Nozick, appear in several other commentaries on (see footnotes 12 and 20 below).

${ }^{7}$ J. Wolff 1991, p. 46

${ }^{8}$ Nozick 1974, p. 102

${ }^{9}$ The assumption of transitivity allows for the free transfer of both rights and obligations between the clients and the DPA, through contractual agreements. For criticism, see Lacey 2001, p. 62
} 
(EBCP). ${ }^{10}$ This principle states that 'If someone knows that doing act A would violate Q's rights unless condition $\mathrm{C}$ obtained, he may not do $\mathrm{A}$ if he has not ascertained that $\mathrm{C}$ obtains through being in the best feasible position for ascertaining this'. ${ }^{11}$ The thought would be that since selfhelp methods of enforcement cannot live up to this principle (only the DPA can be in 'the best feasible position' for ascertaining that $\mathrm{C}$ obtains), the DPA is sanctioned in preventing the independent from using such methods in the exercise of his right to punish.

\section{THE WRONG SANCTION?}

Despite several attributions (both partial and complete) of the above argument to Nozick, he actually explicitly rejects it. But before discussing this rejection, I first wish to note the dilemma that one encounters if one tries to defend the argument from encroachment in its above form. The problem arises when one reflects on the sort of obligations of compensation that the sanctions of either procedural rights or the EBCP leave in their wake. They don't seem to leave any. For procedural rights and the EBCP are more than just sanctions for encroachments, they are fully fledged moral principles which play the same sort of moral role as the right to punish. That is, they delimit the bounds of what one may or may not do in general. They do not (as in the case of sanctions which are not what I have called 'fully fledged moral principles') simply point to an extenuating circumstance which offers a reprieve from some otherwise binding moral requirement.

Thus, if one takes procedural rights or the EBCP as the sanction for the DPA's prohibition, one finds oneself confronted, like J. Wolff and others, with an apparent 'clash of

\footnotetext{
${ }^{10}$ J. Wolff 1991, pp. 61-2: 'Nozick attempts two distinct lines of argument to show that the dominant agency may follow this policy [of prohibiting the independent from employing self-help enforcement methods]. One argument introduces a new concept, specific to issues involving the administration of justice: that of a procedural right. The other argument [the EBCP] relies on more general considerations'.

${ }^{11}$ Nozick 1974, pp. 106-7. See footnote 21 below for the real reason that Nozick introduces the EBCP.
} 
rights'. ${ }^{12}$ But if there is a clash of rights, it seems difficult, perhaps impossible for a libertarian, to explain why the procedural rights of clients, or the EBCP, should take precedence over the independents' right to punish. Libertarianism, with its emphasis on negative rights, manages in general to avoid clashes of rights and so does not rank rights in order of priority. In the event of a clash of rights, the libertarian seems to be at a loss to explain why either should take precedence over the other. Alternatively, as J. Wolff continues, one might say that procedural rights or the EBCP constrain the rights of independents (and everyone else), such that independents do not even have a right to punish unless they can do so without violating procedural rights or the EBCP. But if that is the case, no compensation at all seems to be required according to the compensation for encroachment paradigm, since no right is infringed.

One way that the argument from encroachment could try to avoid this dilemma is by arguing that the sanction is not procedural rights or the EBCP, but rather, the very risk itself of violence being committed against innocent parties due to unreliable methods of prosecution. For this sanction does seem to leave an obligation to compensate in its wake. Lomasky argues convincingly that one can sometimes be sanctioned in encroaching upon a right simply by virtue of one's 'extreme need' ${ }^{13}$ One might think that the mere risk of severe punishment being applied to an innocent (or only mildly punishment deserving) client by an independent using self-help enforcement methods could be seen as creating an appropriately 'extreme need' of protection on the part of clients. If so, this alone could sanction the DPA's prohibiting self-help enforcement and thus encroaching upon independents' rights to punish.

This modified form of the argument from encroachment might seem like the best argument a libertarian could give to defend the conclusion that independents are entitled to

\footnotetext{
${ }^{12}$ See J. Wolff 1991, pp. 65-68. For similar dilemmas along the lines of 'either its wrong or it isn't, in neither case is compensation due', see Holmes 1981, p. 61; Paul 1981, p. 70; and Lacey 2001, p. 64.

${ }^{13}$ Lomasky 1991, pp. 18-19
} 
protection by the DPA. But in fact Nozick explicitly rejects this argument. He does not reject the compensation for encroachment paradigm itself; rather, he rejects the claim that it is applicable in the case of the DPA and the independent.

\section{NOZICK'S REJECTION OF THE ARGUMENT FROM ENCROACHMENT}

There are two principles which are central to Nozickean libertarianism. The first is that, in the absence of some appropriate sanction, an agent does not have the right to intentionally violate the rights of others (even if he pays compensation afterwards). Other agents may coercively prohibit him, without providing compensation, from performing an action which will certainly constitute such a violation. Let us call prohibitions authorised under this principle, compensation free prohibitions. The second principle is that no agent has the right to prohibit other agents from performing actions which will certainly not violate any rights (nor a handful of additional nonrights-based principles, such as the EBCP and the Lockean proviso). Such prohibitions would themselves constitute infringements of rights. As we saw above, agents can sometimes be permitted to infringe others' rights, provided that some moral sanction exists for the infringement. But when a right is infringed, even when such infringement is morally permitted, compensation is payable. As such, an agent who prohibits another from performing a non-rightsviolating action must compensate the agent whom he prohibits. Let us call such prohibitions, compensation requiring prohibitions.

The dilemma that Nozick encounters is that in the case of merely risky actions, one cannot know whether or not a particular action will end up violating any rights until after it has been performed. But if one pre-emptively prohibits such actions, then one will never get the chance to find out. In some cases, including the case of risky self-help enforcement procedures, one may never find out: an independent may convict and punish someone using his self-help 
procedures, yet the accused may go on protesting his innocence until death. So in the case of prohibitions on risky actions, it is impossible to know whether the prohibition ought to be regarded as compensation free or compensation requiring. Risky actions pose, as Nozick notes, 'serious problems for a natural-rights position'. ${ }^{14}$

The argument from encroachment described above oversimplifies the issue by ignoring this epistemological problem. It assumes that a prohibition on self-help enforcement is compensation demanding, because it encroaches upon the rights of independents to punish. But it only encroaches upon this right when it prevents an independent from punishing a guilty person. It does not encroach upon the right when it prevents an independent from punishing an innocent person. The problem is that it is impossible to know which of these alternatives obtains, and thus whether any particular instance of the prohibition's enforcement is compensation demanding or compensation free. ${ }^{15}$ So one cannot just conclude that compensation is owed in the manner normally required by the compensation for encroachment paradigm, and that is the underlying reason why, in contrast to the aforementioned interpretations, Nozick does not endorse but rightly rejects the argument from encroachment.

\section{NOZICK'S SOLUTION: COMPENSATION FOR DISADVANTAGE}

Nozick's own solution to the risky actions dilemma is to invent a whole new paradigm specifically to cover the problematic cases. I will call it the compensation for disadvantage paradigm. The compensation for disadvantage paradigm applies when, and only when, one agent enforces a morally sanctioned prohibition on another agent's risky activities. Nozick suggests that in such cases, we might apply what he calls (somewhat confusingly, since the name doesn't

\footnotetext{
${ }^{14}$ Nozick 1974, p. 74

${ }^{15}$ See Nozick 1974, pp. 103-5
} 
much help us to distinguish these cases from compensation for encroachment cases) the 'principle of compensation', stated thus:

Those who are disadvantaged by being forbidden to do actions that only might harm others must be compensated for these disadvantages foisted upon them in order to provide security for the others. ${ }^{16}$

Disadvantage is to be understood here as being disadvantaged 'compared to the normal situation', not as 'being made worse off than one otherwise would be'. That is to say, one is disadvantaged when one is prevented from performing 'important activities done by almost all', but not when one is prevented from performing one's 'most profitable alternative'. ${ }^{17}$ If an agent suffers no disadvantage through the prohibition, then he is entitled to no compensation. If an agent does suffer a disadvantage through the prohibition, he must be compensated for the disadvantage minus some amount representing the cost he would have expended in performing the prohibited action, were it not prohibited. ${ }^{18}$ Nozick explicitly states on more than one occasion that the compensation for disadvantage paradigm is not to be assimilated to the compensation for encroachment paradigm. For example, he writes that:

\footnotetext{
In order to view the compensation under the principle of compensation as ordinary compensation for a border crossing, one might try to redefine or relocate the border so that it is crossed only when someone is disadvantaged. But it is more perspicuous not to distort our view of this compensation situation by assimilating it to another one.

[... This compensation situation] is not to be assimilated to the border-crossing sort of compensation situation. ${ }^{19}$
}

In the case of the DPA and the independent, the compensation for encroachment paradigm does not apply. Rather, the compensation for disadvantage paradigm applies. (Almost without exception, interpretations of Nozick tend to move without explanation from the claim that the DPA encroaches the rights of independents in enforcing a prohibition on self-help procedures

${ }^{16}$ Nozick 1974 , pp. $82-3$
${ }^{17}$ Nozick 1974 , p. 82
${ }^{18}$ Nozick 1974 , pp. $111-2$
${ }^{19}$ Nozick 1974 , p. 87 ; see also pp. $83-4,86$ 
(which Nozick rejects), to the claim that the DPA must compensate independents for disadvantages imposed on them (which Nozick does say), without ever recognising the significance of the crucial distinction between the two paradigms). ${ }^{20}$ Unreliable self-help enforcement methods are risky, since they risk violating the rights of innocent parties who are wrongly convicted. Thus the DPA 'may treat the unreliable enforcer of justice as it treats any performer of a risky action'. ${ }^{21}$ It may prohibit self-help enforcement, provided that it compensates for any disadvantages caused by the prohibition. Such compensation can be provided by offering the DPA's own protection to independents.

Since the principle of compensation for disadvantage requires only that independents be compensated for disadvantages they suffer relative to the norm, not all independents will be entitled to free compensation by the DPA. ${ }^{22}$ Wealthy independents must pay the full price for the DPA's protection, since they are not made any worse off relative to the norm by having to make such payments: they can pay the full price and still be at least as wealthy as the average person. The financially hard pressed, on the other hand, will indeed require free protection from the DPA to avoid being rendered worse off by the prohibition. Most agents, however, will lie somewhere

\footnotetext{
${ }^{20}$ See, for example, J. Wolff 1991, pp. 66-7; Holmes 1981, pp. 60-1 (claims that the imposition of disadvantage is 'morally wrong' which, for Nozick, is false); R. P. Wolff 1981, pp. 82-3 ('a.' concerns compensation for encroachment paradigm, whereas 'b.' concerns compensation for disadvantage paradigm, yet they are presented as though part of the same argument); and Miller 2002, pp. 22-3 (the supposed 'general premise' is not a premise in Nozick's justification of 'the incorporation of independents into the minimal state').

${ }^{21}$ Nozick 1974, p. 105. Nozick argues that when the performer of a risky action is not financially equipped to offer compensation should his activity result in a violation, or when his action produces uncompensated for fear, he may be prohibited from performing a risky action (pp. 65-71). But Nozick wants to say that the DPA can prohibit self-help enforcement even when the enforcer is in a financial position to compensate, and when he punishes infrequently and so does not produce uncompensated for fear (p. 105). That is the real reason why Nozick introduces the EBCP: in order to be able to say that even those independents can be prohibited from using self help procedures, rather than simply being allowed to continue provided that they pay compensation when miscarriages of justice occur.

${ }^{22}$ So in fact, the minimal state does not quite satisfy the condition originally laid down for statehood, since it still does not garauntee protection to everyone in its territory, regardless of whether or not they pay for it.
} 
between the two extremes and require a partially subsidised protection policy from the state, the size of the subsidy depending on their financial position. ${ }^{23}$

\section{AGAINST COMPENSATION FOR DISADVANTAGE}

Why should we accept the compensation for disadvantage paradigm as a resolution of the dilemma posed by risky actions? Why is it appropriate to compensate agents prohibited from performing such actions only for disadvantages they suffer relative to the norm, rather than to provide some greater or lesser amount of compensation? In particular, how can a libertarian moral framework assign any normative importance to one's situation relative to the norm? Once the dilemma which gives rise to the compensation for disadvantage solution is laid bare, the inadequacy of Nozick's response to the dilemma also becomes apparent.

It is easy to see why Nozick wants to claim that only disadvantages relative to the norm should be compensated for. He explicitly states that he wants to avoid the counterintuitive conclusion that you owe compensation for prohibiting the performance of certain sorts of risky activities like someone's playing Russian roulette on yourself, or using an especially dangerous manufacturing process in a nearby factory. ${ }^{24}$ No disadvantage relative to the norm is suffered by one who is prevented from indulging in such games of Russian roulette, or using the special manufacturing process. On the other hand, a disadvantage relative to how one would have been without the prohibition is suffered by such agents. By deliberately specifying that the compensation for disadvantage paradigm requires only compensation for disadvantages relative to the norm, Nozick seeks to sidestep the conclusion that the Russian roulette player and the

\footnotetext{
${ }^{23}$ Nozick 1974, pp. 111-3. Note that Nozick is here measuring the disadvantage suffered in purely financial terms. This is problematic, since, as Miller 2002, p. 24, argues, independents are disadvantaged by the prohibition not simply because they are unable to protect themselves, but because they are unable to protect themselves in their preferred way.

${ }^{24}$ Nozick 1974, p. 79, 82-3
} 
dangerous manufacturer are owed compensation. But it might be the case that compensation for the Russian roulette player just is one (of several) counterintuitive outcomes of a libertarian moral framework, and a bitter pill that a libertarian simply has to swallow if he is committed to the basic principles of such a position. ${ }^{25}$ Indeed, the introduction of a normative role for one's situation relative to the norm seems entirely arbitrary and unacceptable for a libertarian. Libertarianism specifically excludes ahistorical principles of distribution from its moral framework. $^{26}$ Yet, without offering a justification, Nozick here suddenly grants a role to ahistorical distributional considerations in the principle of compensation for disadvantage. The most appropriate response to the dilemma posed by risky actions for one who wished to remain faithful to the basic principles of libertarianism seems to me not to be the principle of compensation for disadvantage, but rather, the response suggested below.

In the case of risky actions one cannot know whether or not a prohibition on such actions will be compensation demanding or compensation free. Such knowledge would require that one see into the future (or behind the pleas of innocence of the accused), in order to determine whether or not the action would end up violating any rights were it to be performed. One can, however, usually come up with an educated estimate of the probability that the risky action will result in a rights violation, and an estimate of the amount of compensation that would be due if it did. ${ }^{27}$ Thus the most appropriate way to compensate for a prohibition on a risky action would be first to work out how much compensation would be payable for prohibiting the risky action if it

\footnotetext{
${ }^{25}$ Indeed, Nozick (p. 82) admits that even according to the compensation (for disadvantage) principle, we would still have to accept the counter-intuitive conclusion that if a Russian roulette player of this type really is disadvantaged, compensation is owed to him.

${ }^{26}$ See Nozick 1974, pp. 153-5 and following

${ }^{27}$ Nozick discusses the possibility of estimating the risk associated with an action (pp. 74-5) and the risk of an innocent person being convicted by any particular procedure of justice (p. 96-8). But he considers only whether such estimates should have a bearing on whether such activities should be prohibited. He does not even mention the possibility of tying the amount of compensation provided for a prohibition on risky activities to an estimate of the risk associated with the activity.
} 
did not end up causing a violation (that is, by applying the compensation for encroachment paradigm to the prohibition); then to subtract from this amount the best estimate of the compensation that would be due if the risky activity led to a violation (or several violations), discounted by the probability of its doing so. ${ }^{28}$

This result does not change Nozick's conclusion that independents are sometimes entitled to subsidised DPA protection policies. It does, however, change greatly the method of calculating just how large the subsidy ought to be for each independent. In all but a small minority of cases, independents would not, using this new method, be entitled to protection free of charge. The size of the subsidy in any particular case will depend solely on the DPA's best estimate of the risk that the independent, were it not for the prohibition, would have wrongly punished innocent clients (and the best estimate of the severity of that punishment). Such counterfactual calculations may be impossible, but if they are, then I think that that should be considered to be an objection to libertarianism, rather than a vindication of Nozick's principle of compensation. However, they may not be impossible. The DPA could, for example, advertise that it intends to allow self-help procedures that it deems safe to be used, and ask all independents wishing to use a self-help procedure to submit details of their preferred procedure. If the DPA deems a particular independent's procedure unsafe and prohibits that procedure, it will be able to use the information contained in his application to estimate the risk associated with his preferred procedure and thus calculate how much compensation it owes him. ${ }^{29}$

\footnotetext{
${ }^{28}$ Such calculations will doubtless be extremely complex (rather like utilitarian calculations), but probably no more complex than the calculations required by the intricacies of Nozick's principle of compensation (for disadvantage). Note that I leave aside here the difficult issue of what is to count as a 'best estimate'. If a best estimate requires one to be in the best position to make it, one might argue that only the DPA is morally authorised to make such estimates.

${ }^{29}$ If independents refrain from providing information about their preferred procedure, the DPA is entitled to assume that it is so risky as to negate any entitlement to compensation. One might think that all independents will submit applications claiming to prefer unrisky procedures, so as to maximise the amount of compensation they receive. But then they run the risk of having their procedure authorised and having to use a self-help procedure far
} 


\section{CONCLUSION}

The present article has sought to clarify and to appraise Nozick's argument for the minimal state. I argued that Nozick does not, as is often claimed, defend the claim that the DPA owes compensation to independents because it infringes their right to punish those who violate their rights. Rather, Nozick argues that the DPA owes compensation according to his principle of compensation for disadvantage, because it prohibits the risky practice of self-help enforcement, which in any particular instance may or may not result in a rights violation. Nozick is correct to treat self-help enforcement as a type of risky action. However, his principle of compensation for disadvantage, which claims that those prohibited from performing risky actions should be compensated for disadvantages relative to the norm, is arbitrary and unjustifiable in the context of a libertarian moral framework. In contrast, the alternative response to the dilemma of risky actions suggested in the previous section of this article remains faithful to underlying libertarian principles.

less risky (and thus far less likely to find a guilty person guilty, as well as an innocent person) than the one they'd really prefer to use. 


\title{
APPENDIX
}

\section{Prohibition and Compensation in Part I of}

\author{
Anarchy, State, and Utopia
}

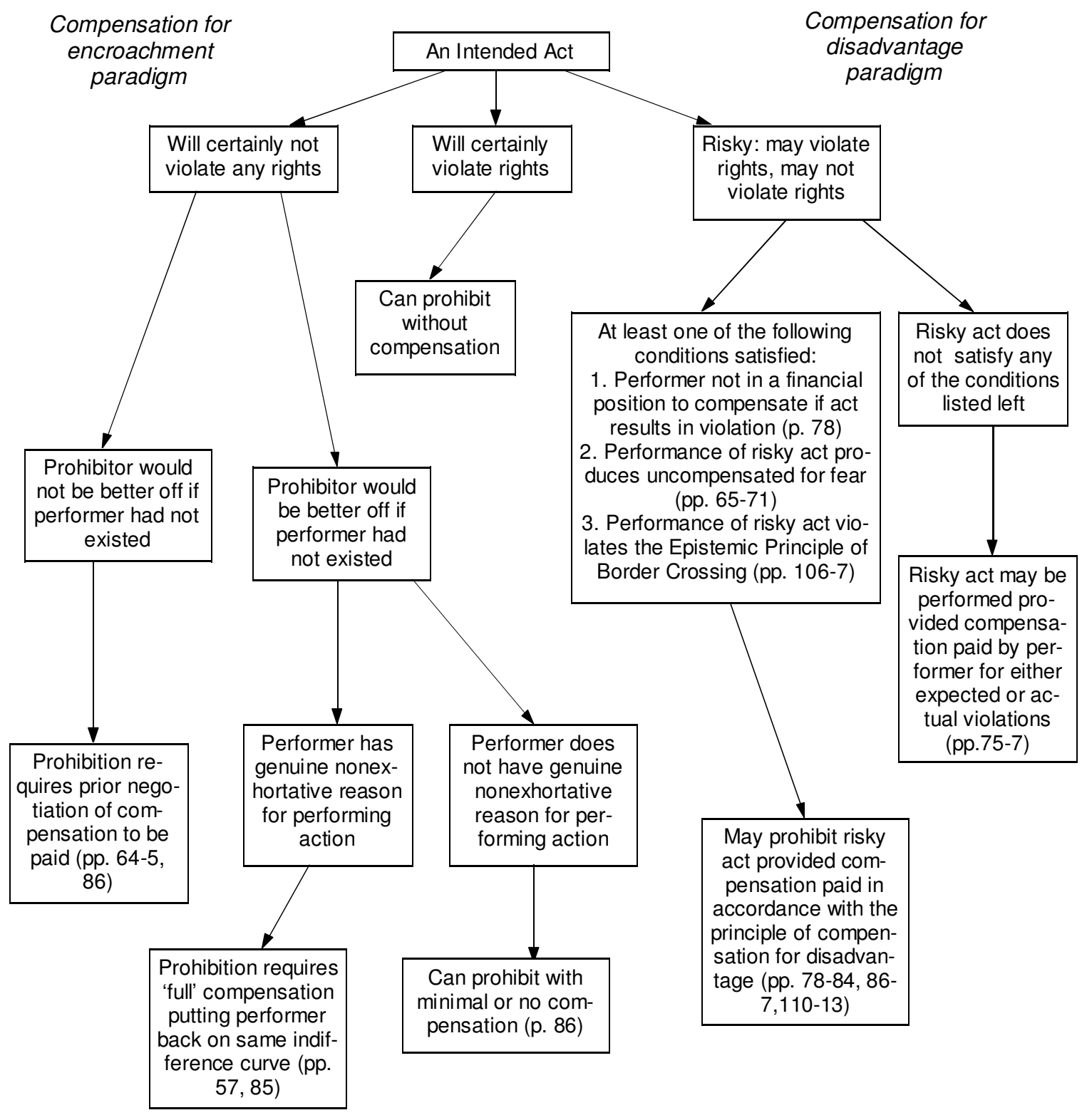




\section{REFERENCES}

Feinberg, Joel. 1978. Voluntary Euthanasia and the Inalienable Right to Life. Philosophy and Public Affairs, 7, 93-102.

Holmes, Richard. 1981. Nozick on Anarchism. Pp. 57-67 in Jeffrey Paul (ed), Reading Nozick: Essays on Anarchy, State and Utopia. Oxford: Basil Blackwell.

Lacey, A. R. 2001. Robert Nozick. Chesham, Bucks: Acumen Publishing Limited.

Lomasky, Loren. 1991. Compensation and the Bounds of Rights. Nomos, 33, 13-44

Miller, David. 2002. The Justification of Political Authority. Pp. 10-33 in David Schmidtz (ed), Robert Nozick. Cambridge: Cambridge University Press.

Nozick, Robert. 1974. Anarchy, State, and Utopia. Oxford: Blackwell Publishers.

Paul, Jeffrey. 1981. The Withering of the State. Pp. 68-76 in Jeffrey Paul (ed), Reading Nozick: Essays on Anarchy, State and Utopia. Oxford: Basil Blackwell.

Thomson, Judith Jarvis. 1986. Some Ruminations on Rights. Pp. 49-65 in William Parent (ed), Rights, Restitution and Risk. Cambridge, Mass: Harvard University Press. Orig. publ. 1977 in University of Arizona Law Review, 19

Wolff, Jonathan. 1991. Robert Nozick: Property, Justice and the Minimal State. Cambridge: Polity Press.

Wolff, Robert Paul. 1981. Robert Nozick's Derivation of the Minimal State, Pp. 77-104 in Jeffrey Paul (ed), Reading Nozick: Essays on Anarchy, State and Utopia. Oxford: Basil Blackwell. 